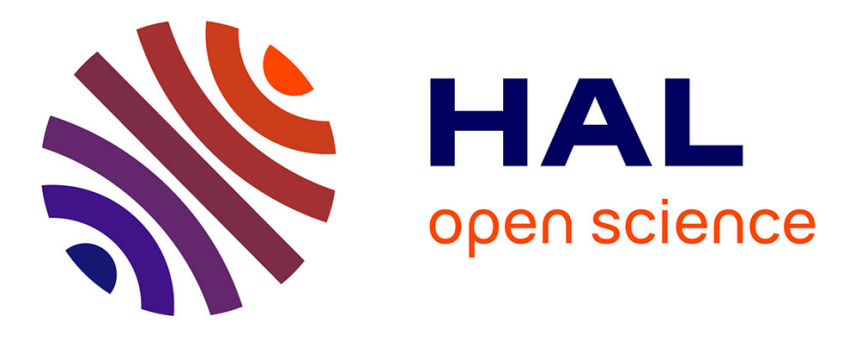

\title{
Tailoring the Oxygen Reduction Activity of Pt Nanoparticles through Surface Defects: A Simple Top-Down Approach
}

Johannes Fichtner, Sebastian Watzele, Batyr Garlyyev, Regina M Kluge, Felix Haimerl, Hany A El-Sayed, Wei-Jin Li, Frédéric Maillard, Laetitia Dubau, Raphaël Chattot, et al.

\section{To cite this version:}

Johannes Fichtner, Sebastian Watzele, Batyr Garlyyev, Regina M Kluge, Felix Haimerl, et al.. Tailoring the Oxygen Reduction Activity of Pt Nanoparticles through Surface Defects: A Simple Top-Down Approach. ACS Catalysis, 2020, 10 (5), pp.3131-3142. 10.1021/acscatal.9b04974 . hal-02931374

\author{
HAL Id: hal-02931374 \\ https://hal.science/hal-02931374
}

Submitted on 6 Sep 2020

HAL is a multi-disciplinary open access archive for the deposit and dissemination of scientific research documents, whether they are published or not. The documents may come from teaching and research institutions in France or abroad, or from public or private research centers.
L'archive ouverte pluridisciplinaire HAL, est destinée au dépôt et à la diffusion de documents scientifiques de niveau recherche, publiés ou non, émanant des établissements d'enseignement et de recherche français ou étrangers, des laboratoires publics ou privés. 
Johannes Fichtner, ${ }^{\mathrm{a}, \mathrm{f}}$ Sebastian Watzele, ${ }^{\mathrm{a}, \mathrm{f}}$ Batyr Garlyyev, ${ }^{\mathrm{a}}$ Regina M. Kluge, ${ }^{\mathrm{a}}$ Felix Haimerl, ${ }^{\mathrm{a}}$ Hany A. El-Sayed, ${ }^{b}$ Wei-Jin Li, ${ }^{\mathrm{c}}$ Frédéric M. Maillard, ${ }^{\mathrm{d}}$ Laetitia Dubau, ${ }^{\mathrm{d}}$ Raphaël Chattot, ${ }^{\mathrm{e}}$ Jan Michalička, ${ }^{\mathrm{f}}$ Jan M. Macak, ${ }^{\mathrm{f}}$ Wu Wang, $, \mathrm{g}, \mathrm{h}$ Di Wang,,${ }^{\mathrm{g}, \mathrm{i}}$ Thomas Gigl, ${ }^{\mathrm{j}}$ Christoph Hugenschmidt and Aliaksandr S. Bandarenka $\mathrm{a}^{\mathrm{a}, \mathrm{k}}$

${ }^{a}$ Physics of Energy Conversion and Storage, Technical University of Munich, James-Franck-Straße 1, 85748 Garching, Germany

${ }^{b}$ Chair of Technical Electrochemistry, Technical University of Munich, Lichtenbergstraße 4, 85748 Garching, Germany

${ }^{c}$ Chair of Inorganic and Metal-Organic Chemistry, Technical University of Munich, Lichtenbergstraße 4, 85748 Garching, Germany

${ }^{d}$ Univ. Grenoble Alpes, Univ. Savoie Mont Blanc, CNRS, Grenoble INP, LEPMI, 38000 Grenoble, France

${ }^{\mathrm{e}}$ ESRF-The European Synchrotron, ID 31 Beamline, 38043 Grenoble, France

${ }^{\mathrm{f}}$ Central European Institute of Technology, Brno University of Technology, Purkynova 123, 61200 Brno, Czech Republic

${ }^{\mathrm{g}}$ Institute of Nanotechnology, Karlsruhe Institute of Technology, Hermann-von-Helmholtz-Platz 1, 76344 Eggenstein-Leopoldshafen, Germany

${ }^{\mathrm{h}}$ Joint Research Laboratory Nanomaterials, Technische Universität Darmstadt, Jovanka-Bontschits-Straße 2, 64287 Darmstadt, Germany

${ }^{i}$ Karlsruhe Nano Micro Facility, Karlsruhe Institute of Technology, Hermann-von-Helmholtz-Platz 1, 76344 Eggenstein-Leopoldshafen, Germany

j FRM II at Heinz Maier-Leibnitz Zentrum (MLZ), Technical University of Munich, Lichtenbergstr. 1, 85748 Garching, Germany

${ }^{\mathrm{k}}$ Catalysis Research Center, Technical University of Munich, Ernst-Otto-Fischer-Straße 1, 85748 Garching, Germany 
KEYWORDS: Electrocatalysis, Fuel Cell, Oxygen Reduction, Platinum Nanoparticles, Top-Down Synthesis

\begin{abstract}
Results from Pt model catalyst surfaces have demonstrated that surface defects, in particular surface concavities, can improve the oxygen reduction reaction (ORR) kinetics. It is, however, a challenging task to synthesize nanostructured catalysts with such defective surfaces. Hence, we present a one-step and up-scalable top-down approach to produce $\mathrm{Pt} / \mathrm{C}$ catalyst (with $\sim 3 \mathrm{~nm} \mathrm{Pt}$ nanoparticle diameter). Using high-resolution transmission electron microscopy and tomography, electrochemical techniques, high energy X-ray measurements and positron annihilation spectroscopy, we provide evidence of a high density of surface defects (including surface concavities). The ORR activity of the developed catalyst exceeds that of commercial Pt/C catalyst, at least 2.7-times in terms of specific $\left(\sim 1.62 \mathrm{~mA} / \mathrm{cm}^{2}{ }_{\mathrm{Pt}}\right.$ at $0.9 \mathrm{~V} v s$ the reversible hydrogen electrode $)$ and at least 1.7-times in terms of mass activity $\left(\sim 712 \mathrm{~mA} / \mathrm{mg}_{\mathrm{Pt}}\right)$, which can be correlated to the enhanced amount of surface defects. Besides, the technique used here reduces the
\end{abstract}


complexity of the synthesis (and therefore production costs) compared to state-of-the-art bottom-up techniques.

\section{Introduction}

With the increased awareness of preventing the climate change, efforts are made to decouple our society's energy demands from the so-called carbon cycle. One promising approach is to reduce emissions caused by automotive combustion engines, for instance by replacing this technology with electric motors that are powered by either batteries and/or hydrogen fuel cells. ${ }^{1,2}$ Even though the market launch of hydrogen fuel cell driven cars is on the rise, further cost reductions are required to make the technology commercially more competitive. Today, anode and cathode catalyst layer of proton exchange membrane fuel cells (PEMFCs) typically consist of Pt-based nanostructures supported on high surface area carbon $(\mathrm{Pt} / \mathrm{C}) .{ }^{3}$ While the hydrogen oxidation reaction taking place at the anode side of the cell is a rapid process, the oxygen reduction reaction (ORR) at the cathode side exhibits sluggish kinetics. In order to improve the activity of such catalysts, two approaches are typically pursued. One way is to alloy Pt nanoparticles 
with less precious transition metal elements (e.g., $\mathrm{Co}, \mathrm{Ni}, \mathrm{Cu}$ ) or lanthanides (e.g., $\operatorname{Pr})_{,}^{4,5,6,7}$ which alters the electronic properties of the catalyst surface by a combination of so-called "strain" and "ligand" effects. This weakens the strong surface-intermediate interactions and allows to optimize electron transfer. ${ }^{8,9}$ In particular, both $\mathrm{Pt}_{3} \mathrm{Ni}$ bulk and nanoscale alloy structures notably exceeded the activity of pure Pt. ${ }^{10,11,12}$ However, due to the dissolution of the solute metal during PEMFC operation (commonly known as "dealloying"), the membrane electrode assembly can get poisoned, resulting in poor long term performance. ${ }^{13}$ Another promising approach is to directly alter the catalytic properties of Pt nanoparticles by the modification of their surface structure. Exemplary, tailoring the size of the nanoparticles and the design of unusual catalyst shapes with enhanced surface area (e.g., hollow nanoparticles, aerogels) can be mentioned. ${ }^{14,15,16}$ Importantly, in such cases the increased activity towards the ORR can, amongst others, also be attributed to the generation of highly active defect-like surface sites. In particular, Calle-Vallejo et al. demonstrated that surface concavities on Pt significantly improve ORR kinetics. ${ }^{17,18}$ This is due to the optimized geometric structure at the concave sites, as quantified by the so-called generalized coordination number $(\overline{C N})$ approach. Particularly 
high $\overline{C N}$ values have been predicted for e.g., hollow or coalescing nanoparticles at their boundary, confirming aforementioned experimental findings. Furthermore, the activity of concave-shaped nanocubes was experimentally demonstrated by $\mathrm{Yu}$ et al., ${ }^{19}$ but the degree of negative curvature was not very pronounced and the size of the concave nanocubes was larger than $20 \mathrm{~nm}$, which results in low mass activity. Furthermore, development of a simple production method for such concave nanoparticles often is a non-trivial endeavor. Current research mainly focuses on the synthesis of such catalysts using conventional bottom-up techniques, which typically suffer from complex and timeconsuming multiple-step procedures. ${ }^{20}$ Hence, the development of a facile synthetic method for Pt nanostructures, which contain these active sites, is a crucial step towards the commercial realization of PEMFC-driven cars on a large scale. Here, we take advantage of a novel top-down synthetic route, in order to prepare $\mathrm{Pt} / \mathrm{C}$ catalysts with a high degree of surface defects. This top-down approach, which was initially discovered decades prior to the beginnings of nanotechnology and introduced as atomization of metal cathodes, ${ }^{21}$ uses high alternating anodic and cathodic biases applied to metal wires immersed in an alkaline electrolyte, in order to produce nanoparticles at the electrode 
surface and subsequently release them into the electrolyte. Fundamental experiments on the nanoparticle synthesis by this approach were provided by Koper's, Li's and Bandarenka's groups in recent years and extended to different types of noble and nonnoble metals as well as alloys and oxide materials. ${ }^{22,23,24,25,26}$ With the help of highresolution transmission electron microscopy (HR-TEM), high-resolution scanning transmission electron microscopy with a high-angle annular detector (HR-STEMHAADF), STEM-HAADF tomography visualization, Rietvield refinement of wide-angle Xray scattering (WAXS), electrochemical techniques and positron annihilation spectroscopy (PAS), we provide evidence that the top-down synthesis leads to the formation of Pt nanoparticles with rough, disordered surfaces. In particular, this includes surface concavities. Furthermore, utilizing the rotating disk electrode (RDE) technique and single-cell PEMFC measurements, we show that Pt/C produced by this top-down approach (denoted as $\mathrm{Pt} / \mathrm{C}_{\mathrm{TD}}$ in the following) is indeed highly active towards the ORR.

\section{Experimental Section}


Synthesis: In a typical synthesis of $\mathrm{Pt} / \mathrm{C}_{\mathrm{TD}}, 20 \mathrm{mg}$ of Vulcan XC72R active carbon (Cabot, USA) were dispersed in $25 \mathrm{ml}$ of a $1 \mathrm{M} \mathrm{KOH}$ (85\%, Grüssing, Germany) solution. To improve the wettability of the carbon support, $\sim 100 \mu \mathrm{l}$ of ethanol (puriss, $>99.8 \%$, Sigma Aldrich, Germany) were added to the suspension, followed by sonication for $15 \mathrm{~min}$. Subsequently, two Pt wires (99,999\%, Goodfellow, Germany) with a diameter of $\sim 0.2 \mathrm{~mm}$ were connected as electrodes and immersed in the suspension under vigorous stirring. To produce Pt nanoparticles, a sinusoidal potential of $\pm 10 \vee v s$ Pt pseudo-reference (frequency: $200 \mathrm{~Hz}$ ) was applied, leading to the erosion of the Pt wires. After generation of the demanded $\mathrm{Pt}$ weight fraction, the suspension was stirred for $12 \mathrm{~h}$ at room temperature, followed by filtering, washing with ultrapure water (Evoqua, Germany) and drying in the oven at $60^{\circ} \mathrm{C}$. As a reference catalyst, TEC10V20E Pt/C (19.6 wt.\%) from Tanaka Kikinzoku Kogyo (Pt/ $\left.\mathrm{C}_{\mathrm{TKK}}\right)$ was used without further modification.

$\mathrm{Pt}$ on carbon weight loading: The weight fraction of $\mathrm{Pt}_{\mathrm{TD}}$ nanoparticles on carbon was determined using TGA. The measurements were carried out with a METTLER TOLEDO TG-MS coupling instrument with an air flow of $50 \mathrm{ml} / \mathrm{min}$ and heating speed of $50 \mathrm{~K} / \mathrm{min}$ 
to $1100^{\circ} \mathrm{C}$. Prior to ramping the temperature, the sample was dried at $\sim 135^{\circ} \mathrm{C}$, followed by determination of its initial weight. Before cooling down, the sample was kept at $1100^{\circ} \mathrm{C}$ for 50 minutes until no further weight loss could be observed. The mass was compared after cooling down to $135^{\circ} \mathrm{C}$.

Electron microscopy: For TEM imaging of the $\mathrm{Pt} / \mathrm{C}_{\mathrm{TD}}$ electrocatalyst, a Philips CM100 EM, operated at $100 \mathrm{kV}$, was used. The samples were prepared by sonicating the catalyst powder in isopropanol, followed by drop-casting the dispersion on formvar-supported carbon-coated Cu400 TEM grids (Science Services, Germany). HR-(S)TEM imaging of the unsupported $\mathrm{Pt}_{\mathrm{TD}}$ nanoparticles was conducted on a TITAN Themis $60-300$ (ThermoFisher Scientific, USA) operated at $300 \mathrm{kV}$ and equipped with a Schottky FEG type emission gun, a spherical aberration corrector for the objective lens and HAADF detector (Fischione, USA). The TEM sample of the unsupported $\mathrm{Pt}_{\mathrm{TD}}$ nanoparticles was prepared from Pt nanoparticles dispersed in ultrapure water by sonication for 15 minutes, which were immediately dripped on a copper TEM grid with quantifoil holey carbon membrane covered by graphene oxide. The HR-TEM and HR-STEM images were 
acquired using the software Velox v.2.6 (ThermoFisher Scientific, USA) and Fourier filtering was performed using masks on selected spots in fast Fourier transformation (FFT) patterns in the software Digital Micrograph GSM 2 (Gatan Inc., USA). The tomography of the unsupported $\mathrm{Pt}_{\mathrm{TD}}$ nanoparticles was conducted on a TITAN 80-300 (FEl company, USA) operated at $300 \mathrm{kV}$ in STEM mode using the HAADF detector, which allows imaging with high contrast between Pt nanoparticles and the carbon membrane of the TEM grid. The same sample as for TEM analysis (described above) was used, but round Au tracking nanoparticles with $\sim 6.5 \mathrm{~nm}$ in size, dissolved in high-purity water, were dripped on the grid additionally to allow later alignment of the images in the whole tilting range. The used tilting range was $+/-72^{\circ}$ and the STEM-HAADF images were taken in $2^{\circ}$ steps. A 2020 high field-of-view single-tilt tomography holder (Fishione, USA) was used for the tomography tilt series acquisition. The tomography data were obtained using the corresponding STEM tomography data acquisition software v.4.1 (ThermoFisher Scientific, USA) with automatic and dynamic focusing. The post processing of the tomography data consisted of three parts: alignment, reconstruction and visualization. The alignment was performed using the open-source software IMOD v.4 (University of 
Colorado, USA) with plugin eTomo, where a fiducial model was created by manual tracking of $\mathrm{Au}$ beads surrounding the structure of interest with a residual error of the alignment of 1.2 pixel. The reconstruction was performed using the software Inspect3D v.3.1 (FEl company, USA) from the previously aligned dataset and a $3 \mathrm{D}$ volume of the desired size was created. The final colorful visualization of reconstructed volume was performed using the software AMIRA (ThermoFisher Scientific, USA).

Electrochemical measurements: Electrocatalytic activity measurements were performed using a standard electrochemical cell, filled with $0.1 \mathrm{M} \mathrm{HClO}_{4}$ (Suprapur®, Merck, Germany) as electrolyte. The cell was frequently cleaned with a 3:1 ratio of sulfuric acid and hydrogen peroxide, followed by boiling the cell with ultrapure water. Electrochemical measurements were conducted using a BioLogic VSP-300 (BioLogic, France) potentiostat. As a substrate for $\mathrm{Pt} / \mathrm{C}_{\mathrm{TD}}$, a glassy carbon electrode with a diameter of $5 \mathrm{~mm}$ and an area of $0.196 \mathrm{~cm}^{2}$ (Pine instruments, USA) in combination with a Pine MSR electrode rotator (Pine instruments, USA) was used. For electrochemical studies, freshly prepared catalyst inks were used. A typical catalyst ink ratio consisted of $\sim 10$ mg finely 
grinded catalyst powder, $3.6 \mathrm{ml}$ of ultrapure water, $1.466 \mathrm{ml}$ of isopropanol (puriss., $>99.8 \%$, Sigma Aldrich, Germany) and $0.03 \mathrm{ml}$ of Nafion dispersion (5 wt.\% in lower aliphatic alcohols and water, Sigma Aldrich, Germany). To obtain a homogeneous dispersion, the inks were sonicated for 20 minutes prior to their first use. Prior to usage, the electrode was polished with alumina paste $(1.0,0.3$, and $0.05 \mu \mathrm{m})$ and rinsed with ultrapure water. A commercial mercury/ mercurous sulfate electrode (Schott, Germany) served as reference electrode. A Pt wire $(99.9 \%$, Goodfellow, Germany) served as counter electrode. It has to be noted that CO-stripping voltammetry was recorded in a slightly modified setup. As a reference electrode, a commercial Hydroflex® hydrogen electrode (Gaskatel, Germany) was utilized. Experiments were operated with an Autolab PGSTAT302N potentiostat (Metrohm, France).

\section{Membrane electrode assembly measurements:}

Single-cell PEMFC measurements were conducted in a home-made cell setup. Fuel cell performance was evaluated on a Greenlight Innovation G60 test station (Greenlight Innovation 
Corp., Canada), coupled with a Gamry reference 3000 potentiostat (Gamry Instruments, USA). 5 $\mathrm{cm}^{2}$ catalyst layers were prepared using the decal transfer method, i.e., by rod coating on a PTFE decal, followed by drying at room temperature. As anode catalyst, commercial $\mathrm{Pt} / \mathrm{C}_{\mathrm{TKK}}$ (TEC10V20E) with an anode loading of $0.08 \mathrm{mg}_{\mathrm{Pt}} / \mathrm{cm}^{2}$ was used. As cathode catalyst, $\mathrm{Pt} / \mathrm{C}_{\mathrm{TD}}$ with a cathode loading of $0.1 \mathrm{mg}_{\mathrm{Pt}} / \mathrm{cm}^{2}$ was utilized. Synthesis of $\mathrm{Pt} / \mathrm{C}_{\mathrm{TD}}$ electrocatalyst was conducted as described in the previous sections, however, the batch size was increased from $\sim 20 \mathrm{mg}$ to $\sim 100$ $\mathrm{mg}$ of $\mathrm{Pt} / \mathrm{C}_{\mathrm{TD}}$. For ink preparation, the catalyst was dispersed in a mixture of 1-propanol and water $(\sim 10 \mathrm{wt} \%)$ and an ionomer (Nafion, $5 \% \%_{\mathrm{wt}}$ in lower aliphatic alcohols and water, Sigma Aldrich, Germany ) to carbon (I/C) ratio of 0.65 was adjusted. The ink was mixed on a roller mill for $18 \mathrm{~h}$ at room temperature, using $\mathrm{ZrO}_{2}$ beads. Anode, $15 \mu \mathrm{m}$ membrane and cathode were hot-pressed for $3 \mathrm{~min}$ at $155^{\circ} \mathrm{C}$ and $4 \mathrm{kN}$. A Freudenberg H14C7 (Freudenberg \& Co. KG, Germany) served as the gas diffusion layer. To record CO-stripping voltammograms, the cell was purged with 10\% $\mathrm{CO}$ in $\mathrm{N}_{2}$ for $\sim 10$ min at a constant potential of $0.1 \mathrm{~V}$, followed by purging with pure $\mathrm{N}_{2}$ to remove excess of $\mathrm{CO}$. The voltammograms were recorded at a scan rate of $100 \mathrm{mV} / \mathrm{s}$. Differential flow $\mathrm{H}_{2} / \mathrm{O}_{2}(2000 \mathrm{nccm} / 5000 \mathrm{nccm})$ polarization curves were recorded at $80^{\circ} \mathrm{C}, 170 \mathrm{kPa}$ abs and $100 \%$ relative humidity. The ohmic resistance was determined via electrochemical impedance spectroscopy. The $\mathrm{H}_{2}$ crossover was determined in $\mathrm{H}_{2} / \mathrm{N}_{2}$ atmosphere.

Positron annihilation spectroscopy: For the present study, coincident Doppler broadening spectroscopy (CDBS) was performed at the CDB spectrometer using the mono-energetic positron beam at NEPOMUC located at the research neutron source Heinz Maier-Leibnitz (FRM II). ${ }^{27}$ The positron implantation energy was varied between 0.10 and $30 \mathrm{keV} .{ }^{28,29}$ In 
order to examine the near surface region, small energy steps of 0.10 and $0.20 \mathrm{keV}$ were chosen up to an implantation energy of $8 \mathrm{keV}$. The energy of the emitted annihilation radiation was recorded by high-purity Ge detectors with a typical energy resolution of 1.30 $\mathrm{keV}$ at $511 \mathrm{keV}$. For the calculation of the $\mathcal{S}$-parameter the central energy interval was set to $(511 \pm 0.85) \mathrm{keV}$. The CDB spectra were recorded at a positron implantation energy of $0.4 \mathrm{keV}$ where the contribution of the Si substrate can be neglected according to the calculated Makhov profile. Preparation of the samples was performed by dispersing 10 $\mathrm{mg}$ of $\mathrm{Pt} / \mathrm{C}_{\mathrm{TD}}$ and commercial $\mathrm{Pt} / \mathrm{C}_{\mathrm{TKK}}$ catalyst powder in $1 \mathrm{ml}$ of ethanol via sonication. The as-prepared inks were drop-casted onto a silicon wafer, followed by drying of the sample at $60^{\circ} \mathrm{C}$ for $1 \mathrm{~h}$.

WAXS measurements and Rietveld refinement: WAXS patterns of $P t / C_{T D}$ and the commercial $\mathrm{Pt} / \mathrm{C}_{\mathrm{TKK}}$ were measured at the ID31 beamline of the European synchrotron radiation facility (ESRF, Grenoble, France). High energy X-ray radiations of $70 \mathrm{keV}$ were focused on the catalyst powder contained either in a Kapton® tape (powder film removed from a rotating disk electrode) or Kapton® capillary for $\mathrm{Pt} / \mathrm{C}_{\mathrm{TD}}$ and commercial $\mathrm{Pt} / \mathrm{C}_{\mathrm{TKK}}$, 
respectively. The scattered signal was collected using a Dectris Pilatus CdTe 2M detector within $5 \mathrm{~s}$ exposure time. The 2D signal was azimuthally integrated and reduced to a 1D curve using the pyFAl software package after the energy, ${ }^{30}$ detector distance and tilt were calibrated using a standard $\mathrm{CeO}_{2}$ powder. The lattice parameter, crystallite size and microstrain values for the electrocatalysts were estimated by Rietveld refinement of the WAXS patterns using an Fm3m structure of metallic Pt and the Fullprof software. ${ }^{31}$ Due to an external pollution by $\mathrm{Ni}$, an additional $\mathrm{Ni}$ phase was added to refine $\mathrm{Pt} / \mathrm{C}_{\mathrm{TD}}$. The instrument resolution function was determined from the $\mathrm{CeO}_{2}$ standard WAXS pattern, the peak shape and the background were described using the Thompson-Cox-Hastings (TCH) function and by a polynomial function, respectively. A possibility for uniaxial anisotropic description of nanoparticle size along the [111] direction axis was also implemented.

\section{Results and Discussion}

During the top-down synthesis process (see Figure 1A), Pt wires are exposed to strongly polarizing, alternating voltages. Thereby, nanoparticles can be rapidly eroded from the 
wire surface and subsequently be released into the electrolyte. Due to the rough conditions of our synthetic route, we assume to produce a wide variety of nanoparticle shapes, including surface concavities, combined with the introduction of local strain. In order to investigate the surface-defective character of $\mathrm{Pt} / \mathrm{C}_{\mathrm{TD}}$, five different approaches were exploited:

1. HR-(S)TEM was used to visualize certain defective surface sites of unsupported $\mathrm{Pt}_{\mathrm{TD}}$ nanoparticles.

2. STEM-HAADF tomography visualization was performed to obtain 3D information about the disordered surface regions of unsupported $\mathrm{Pt}_{\mathrm{TD}}$ nanoparticles.

3. PAS was employed to compare the defect concentration of $\mathrm{Pt} / \mathrm{C}_{\mathrm{TD}}$ to commercial $\mathrm{Pt} / \mathrm{C}_{\mathrm{TKK}}$ (detailed information about the reference catalyst is given in the experimental section).

4. Rietveld refinement of WAXS measurements was performed to investigate and quantitatively compare the defect-induced degree of microstrain of $P t / C_{T D}$ to commercial $\mathrm{Pt} / \mathrm{C}_{\mathrm{TKK}}$. 
5. Electroanalytical methods were used to monitor and compare structural defects and activities of both samples.
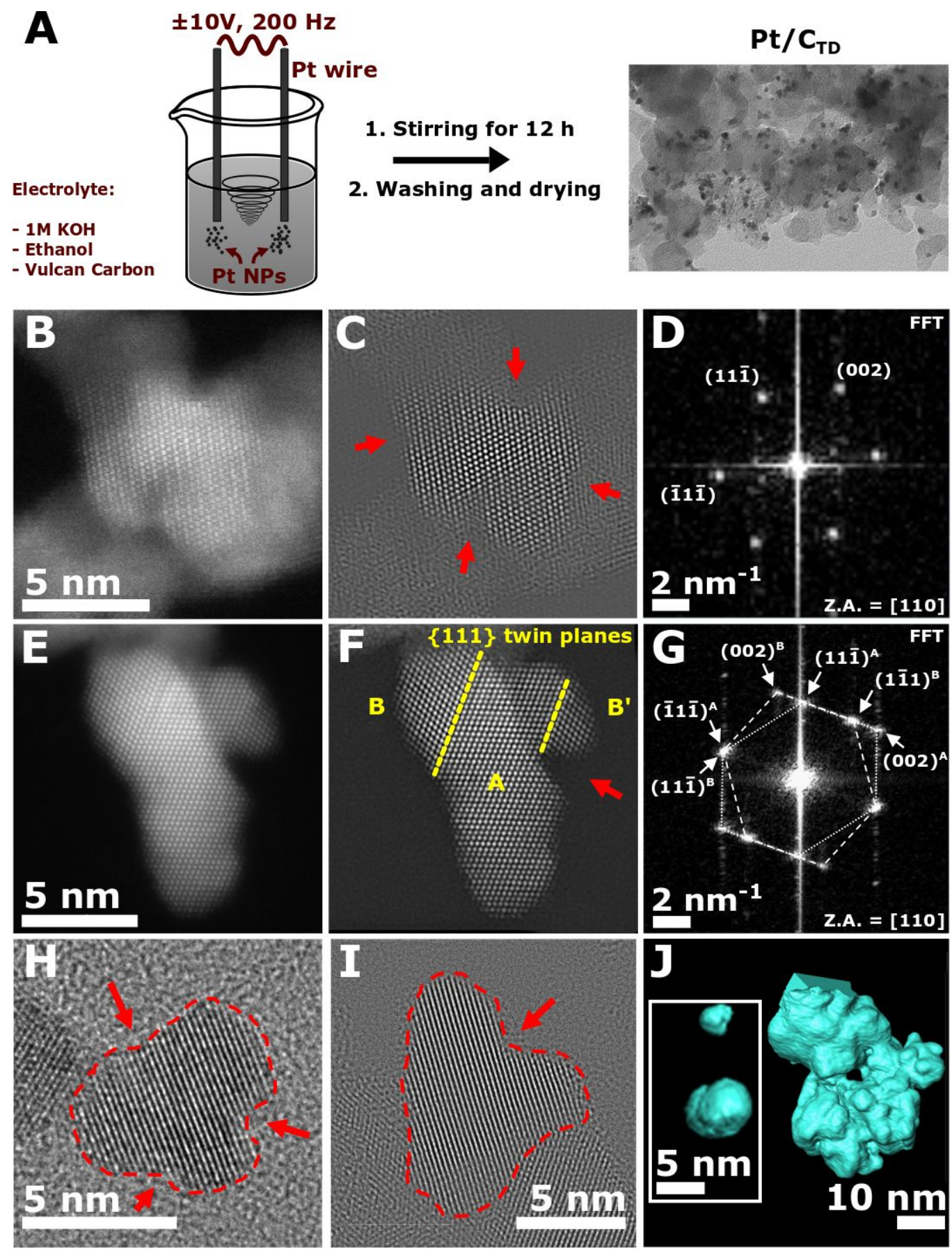
Figure 1. (A) Schematic description of the synthetic procedure towards $P t / C_{T D}$ electrocatalyst. Application of an alternating sinusoidal potential $( \pm 10 \mathrm{~V}, 200 \mathrm{~Hz})$ to $\mathrm{Pt}$ wires immersed in a suspension of Vulcan carbon in $1 \mathrm{M} \mathrm{KOH}$ and ethanol under vigorous stirring leads to the formation of carbon supported Pt nanoparticles. $(B, E) H R$ STEM images of unsupported $\mathrm{Pt}_{\mathrm{TD}}$ single nanoparticles with corresponding $(\mathrm{C}, \mathrm{F})$ Fourier filtered images and $(D, G) F F T$ patterns (Z.A. = zonal axis). Certain concavities are highlighted by red arrows. Twin boundaries and twin grains $A, B, B^{\prime}$ are marked in (F). $(\mathrm{H}, \mathrm{I}) \mathrm{HR}$-TEM images of unsupported $\mathrm{Pt}_{\mathrm{TD}}$ nanoparticles. Concave regions are highlighted by red arrows. (J) 3D visualization of two unsupported, single $\mathrm{Pt}_{\mathrm{TD}}$ nanoparticles, as well as a fraction of unsupported nanoparticle agglomerate, using STEM-HAADF tomography. Several concave regions are visible on both the individual as well as on the agglomerated nanoparticles.

In Figure 1B-I, unsupported Pt single nanoparticles are characterized with use of HRTEM and HR-STEM imaging. The images reveal a non-spherical structure of the 
nanoparticles produced. Indeed, several concave-shaped surface regions can be found, as exemplary highlighted by red arrows. In detail, several complex shapes of the nanoparticles were found, as it is demonstrated by two nanoparticles imaged by HRSTEM-HAADF technique in Figure $1 \mathrm{~B}$ and $\mathrm{E}$, where smaller concavities in the order of few crystal lattice planes and a sharp, deep concavity were revealed. These defects are highlighted in Figure $1 \mathrm{C}$ and F, respectively, where a Fourier filtering was used to reduce noise in original HR-STEM images to improve visibility of the atomic structure details. FFT patterns of both nanoparticles (Figure 1D and G), which were obtained from the original HR-STEM images, show spots corresponding to platinum $\{111\}$ and $\{002\}$ lattice planes with spacing of $0.227 \mathrm{~nm}$ and $0.196 \mathrm{~nm}$, respectively, ${ }^{32}$ and crystal orientation of the nanoparticles to zone axis [110] of the face-centered cubic (FCC) lattice. The nanoparticle in Figure 1B was found to be a pure single crystal, while in the case of the nanoparticle in Figure $1 \mathrm{E}$ a twinned structure was revealed by FFT. The FFT in Figure $1 \mathrm{G}$ shows two [110] FCC zone axis patterns (marked by lattice indexes "A" and "B" and by dotted and dashed lines), which are rotated with respect to each other around the common $\{111\}$ twin plane. Hand to hand to this finding, twinning of the nanoparticle by two corresponding 
planes of the $\{111\}$ type was identified, which divides the crystal into three twin grains $A$, $\mathrm{B}$ and $\mathrm{B}^{\prime}$, as it is marked in Figure 1F. In addition, the complex shape of the nanoparticles can be seen from a variation in contrast within both crystals imaged by the HR-STEMHAADF technique in Figure $1 \mathrm{~B}$ and $\mathrm{E}$. The resulting contrast at the used imaging conditions is predominantly dependent on atomic number $Z$ and thickness of the sample. ${ }^{33}$ As the studied nanoparticles are pure Pt crystals, the contrast variations must originate from variations of the sample thickness. Therefore, it is also possible to demonstrate the topological complexity of both nanoparticles. Figure $1 \mathrm{H}$ and I show HRTEM images of two Pt nanoparticles with "strawberry"-like shape, including up to three concave surface regions, which can be considered particularly interesting for electrocatalytic applications. To judge the complexity of the nanoparticle shapes in broader view, a state-of-the-art STEM-HAADF tomography technique, utilized for the visualization of complex 3D samples with high lateral resolution, was performed on unsupported $\mathrm{Pt}_{\mathrm{TD}}$ nanoparticles. The final 3D visualization of top-down synthesized single nanoparticles confirms the presence of surface concavities, as it is exemplarily illustrated in Figure 1J (left). Moreover, it is visible that surface concave regions appear on both, 
smaller particles, as well as on larger particles. Even though the unsupported nanoparticles tend to agglomerate, the used tomography technique revealed the irregular shape of many individual nanoparticles on surface of a bigger nanoparticle cluster, as it is illustrated in Figure $1 \mathrm{~J}$ (right side). Compared to the typically spherically shaped commercial Pt nanoparticles such as the reference catalyst, ${ }^{34,35,36}$ the complex shapes of $\mathrm{Pt}_{\mathrm{TD}}$ nanoparticles prefigure an activity increase. However, a representative quantification of the particularly active sites is not possible due to the individual character of each single nanoparticle. 

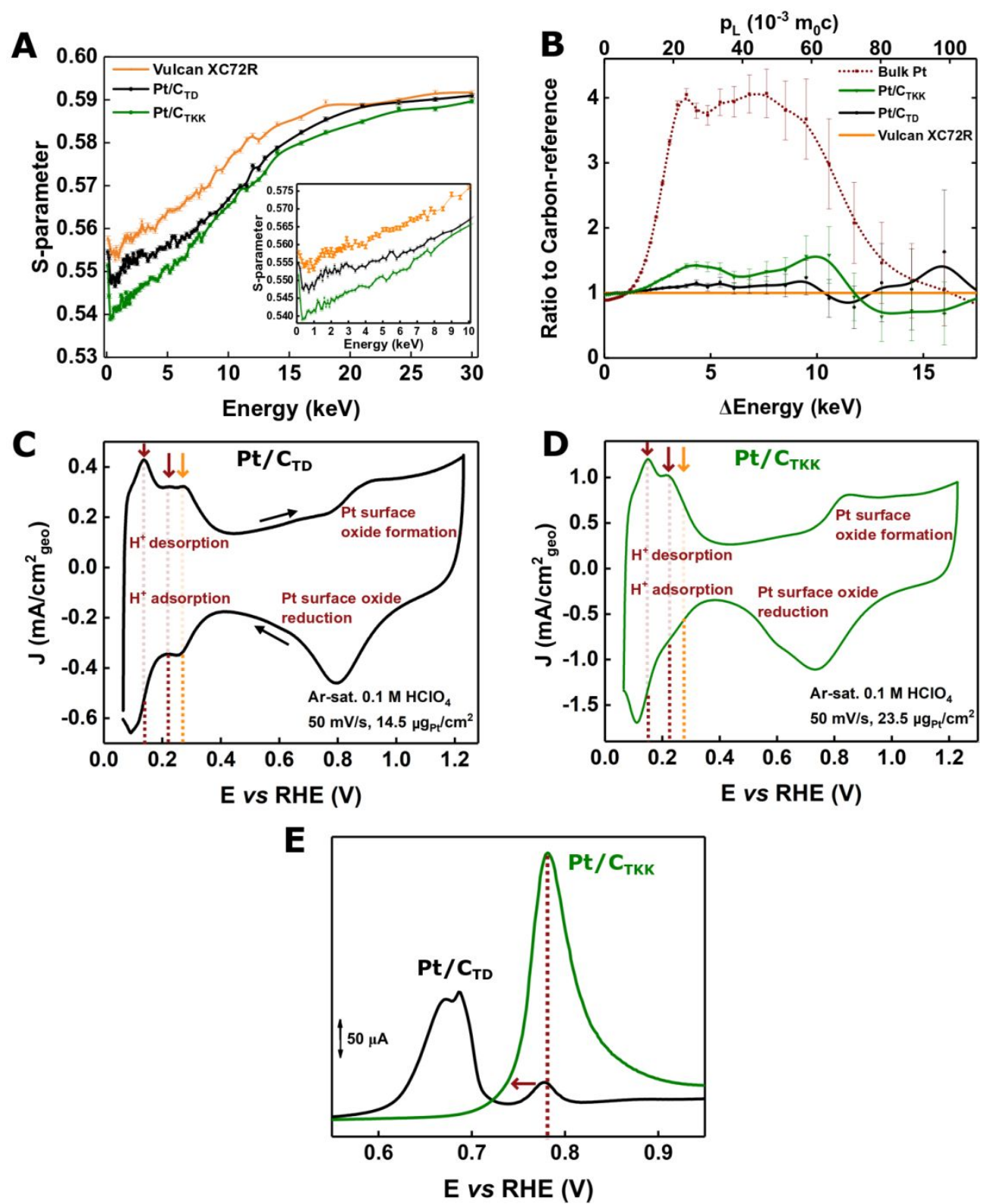

Figure 2. (A) $S$-parameter as a function of the positron implantation energy obtained from DBS measurement. Near the surface, i.e., at low implantation energies, $\mathrm{Pt} / \mathrm{C}_{\mathrm{TD}}$ shows a significantly higher $\mathcal{S}$-parameter than commercial $\mathrm{Pt} / \mathrm{C}_{\text {TKK. }}$. The higher $\mathcal{S}$ parameter is mainly attributed to the higher defect concentration of $\mathrm{Pt} / \mathrm{C}_{\mathrm{TD}}$. The inset 
shows a magnified energy range of $0-10 \mathrm{keV}$. (B) Ratio curves normalized to the curve of the carbon reference obtained by $\mathrm{CDBS}$. $\mathrm{Pt} / \mathrm{C}_{\mathrm{TD}}$ shows a much lower $\mathrm{Pt}$ signature (7.5\%) compared to its commercial counterpart (18.2\%). Hence, the positron annihilation probability with $\mathrm{Pt}$ core electrons is significantly decreased in $\mathrm{Pt} / \mathrm{C}_{\mathrm{TD}}$, which is ascribed to a higher defect concentration. (C,D) Typical CVs of $\mathrm{Pt} / \mathrm{C}_{\mathrm{TD}}$ and commercial Pt/C $\mathrm{CKK}_{\mathrm{TK}}$, respectively. Electrolyte: Ar-saturated $0.1 \mathrm{M} \mathrm{HClO}_{4}$. Scan rate: 50 $\mathrm{mV} / \mathrm{s}$. Red arrows indicate typical $\mathrm{H}_{\text {UPD }}$ peak positions of $\mathrm{Pt} / \mathrm{C}_{\text {TKK. }} \cdot \mathrm{Pt} / \mathrm{C}_{\mathrm{TD}}$ shows an additional peak shoulder (orange arrow), which indicates the presence of surface structural defects (see main text). (E) CO-stripping peaks of $\mathrm{Pt} / \mathrm{C}_{\mathrm{TD}}$ (black curve) and commercial $\mathrm{P} t / \mathrm{C}_{\text {TKK }}$ (green curve). The peak shift indicates the presence of surface structural defects. It has to be noted that the CO-stripping voltammograms were recorded separately, using a slightly modified setup (see experimental section). COcoverage was achieved by bubbling $0.1 \mathrm{M} \mathrm{HClO}_{4}$ with pure $\mathrm{CO}$ for $\sim 6$ minutes while applying a constant potential of $0.1 \mathrm{~V} v s \mathrm{RHE}$. Saturation of the electrolyte with Ar for 
$\sim 30 \mathrm{~min}$, followed by a subsequent performance of a full CV cycle further leads to the oxidation of the $\mathrm{CO}$ monolayer. Scan rate: $20 \mathrm{mV} / \mathrm{s}$.

In order to expand the study of single nanoparticles to the whole system, PAS was employed. It was chosen to examine the defective character of $\mathrm{Pt} / \mathrm{C}_{\mathrm{TD}}$ in comparison to commercial $\mathrm{Pt} / \mathrm{C}_{\mathrm{TKK}}$. PAS is known as a powerful, non-destructive tool to detect open volume defects, i.e., vacancies or vacancy clusters in a crystal lattice. Due to the effective trapping of positrons in such crystal defects, the positron is applied as highly-mobile micro-probe with outstanding sensitivity to vacancy concentrations as low as $10^{-7}$ in metals. ${ }^{37}$ For the present study, a low-energy positron beam is required in order to investigate the near-surface region of the $\mathrm{Pt} / \mathrm{C}$ samples. For better understanding, some elementary parts of PAS will be explained in the following text, whereas further details can be found in the literature. ${ }^{38,39}$ After being implanted in a solid, positrons thermalize within picoseconds and can then diffuse quasi-freely through the crystal lattice within a diffusion length typically in the order of $100 \mathrm{~nm}$. They eventually annihilate with a core or valence electron either in the unperturbed crystal lattice or after being trapped at defect 
sites. The positron-electron annihilation leads predominantly to a back-to-back emission of two $511 \mathrm{keV} \mathrm{y}$-quanta in the center-of-mass-system. These $\mathrm{\gamma}$-quanta are most important for gaining information about defects, as they will be detected during the experiment. In the laboratory system, the longitudinal component of the electron momentum $\left(\mathrm{p}_{\mathrm{L}}\right)$ causes a Doppler-shift of the annihilation quanta. The resulting broadened annihilation photo peak, i.e., recorded counts as a function of $\mathrm{Y}$-energy, is analyzed in DBS. For quantitative analysis of the line shape, the so-called $S$-parameter is commonly applied, which is defined as the fraction of counts in a fixed central region around the $511 \mathrm{keV}$ annihilation peak. Since the central part of the annihilation peak is dominated by positrons annihilating preferably with low-momentum valence electrons, the S-parameter increases with an increasing number of vacancies or vacancy clusters. ${ }^{40}$ In CDBS, both $y$-quanta of an annihilation event are detected simultaneously in a collinear detector setup. Due to the effective suppression of the background, the annihilation of high momentum (core) electrons becomes experimentally accessible, i.e., chemical information can be gained from the surrounding of the annihilation site. For evaluation, CDB spectra are normalized, mirrored at $511 \mathrm{keV}$ and usually divided by a reference 
spectrum in order to obtain so-called ratio curves in which the elemental signatures can be clearly observed.

Figure 2A shows the $S$-parameter as a function of the positron implantation energy, which is a measure of the probed sample depth. ${ }^{41}$ Towards high energies ( $>25 \mathrm{keV}$ ), the commercial carbon reference material (Vulcan XC72R) in form of carbon nanoparticles with a particle size between $30-60 \mathrm{~nm},{ }^{42}$ as well as both the commercial $\mathrm{Pt} / \mathrm{C}_{\mathrm{TKK}}$ and $\mathrm{Pt} / \mathrm{C}_{\mathrm{TD}}$ nanoparticles supported on Vulcan carbon approach the same $S$-parameter. This is expected since at higher energy the positrons are implanted with a higher implantation depth, i.e., most of the positrons annihilate in the Si substrate. At low energies $(<20 \mathrm{keV})$, the carbon reference possesses a higher $\mathcal{S}$-parameter than both the commercial $\mathrm{Pt} / \mathrm{C}_{\mathrm{TKK}}$ and $\mathrm{Pt} / \mathrm{C}_{\mathrm{TD}}$. This can be ascribed to the generally lower $\mathcal{S}$-parameter of $\mathrm{Pt}$ compared to the carbon reference, as also observed in the normalized projection of the CDB spectra (Figure S1) and the low-energy region of the ratio curves (Figure 2B). More interesting, comparing both samples, $\mathrm{Pt} / \mathrm{C}_{\mathrm{TD}}$ shows a significantly higher $S$-parameter than commercial $\mathrm{Pt} / \mathrm{C}_{\mathrm{TKK}}$. For the interpretation, it has to be mentioned that $\mathrm{Pt} / \mathrm{C}_{\mathrm{TD}}$ and 
commercial $\mathrm{Pt} / \mathrm{C}_{\mathrm{TKK}}$ slightly differ in $\mathrm{Pt}$ on carbon weight fraction (thermogravimetric analysis $[\mathrm{TGA}]$ reveals $\sim 15$ wt. $\%$ for $\mathrm{Pt} / \mathrm{C}_{\mathrm{TD}}$ and $\sim 20$ wt. $\%$ for the commercial $\mathrm{Pt} / \mathrm{C}_{\mathrm{TKK}}$ ), whereas the overall Pt loading on the substrate was adjusted. Therefore, due to its slightly smaller $\mathrm{Pt}$ content a slightly higher $\mathcal{S}$-parameter of $\mathrm{Pt} / \mathrm{C}_{\mathrm{TD}}$ compared to commercial $\mathrm{Pt} / \mathrm{C}_{\mathrm{TKK}}$ was expected. However, the significantly higher $S$-parameter of $\mathrm{Pt} / \mathrm{C}_{\mathrm{TD}}$ cannot be caused by only the comparably small difference in weight fractions of the samples with similar overall Pt loading. Instead, this effect is attributed to a higher concentration of (open-volume) defects in $\mathrm{Pt} / \mathrm{C}_{\mathrm{TD}}$ than in commercial $\mathrm{Pt} / \mathrm{C}_{\mathrm{TKK}}$. In order to additionally access the element-specific high-momentum part of the annihilation line related to core electrons, CDBS was carried out. Figure $2 \mathrm{~B}$ shows the ratio curves of $\mathrm{Pt} / \mathrm{C}_{\mathrm{TD}}$ and commercial $\mathrm{Pt} / \mathrm{C}_{\mathrm{TKK}}$ samples. These ratio curves are obtained by normalizing the individual CDBS raw spectra to same intensity and subsequent division by a reference spectrum, which is in this case a CDBS spectrum of a carbon reference. For comparison, a spectrum obtained for a bulk $\mathrm{Pt}$ reference is shown as well. For both, $\mathrm{Pt} / \mathrm{C}_{\mathrm{TKK}}$ and $\mathrm{Pt} / \mathrm{C}_{\mathrm{TD}}$, the typical signature of $\mathrm{Pt}$ is visible $\left(\mathrm{pL}=10-80 \times 10^{-3} \mathrm{~m}_{0} \mathrm{c}\right)$. Assuming a simple model that positrons annihilate either in defect-free $\mathrm{Pt}$ or carbon, one would expect that the 
respective Pt signal relates to the measured Pt weight fractions (see TGA result above), i.e., the $\mathrm{Pt}$ signatures in $\mathrm{Pt} / \mathrm{C}_{\mathrm{TD}}$ would amount to 0.75 of that in $\mathrm{Pt} / \mathrm{C}_{\mathrm{TKK}}$. As determined by fitting the curves (see $\mathrm{SI})$, however, the $\mathrm{Pt}$ signature in $\mathrm{Pt} / \mathrm{C}_{\mathrm{TD}}(7.5 \%)$ is 0.59 less distinct than in the commercial $\mathrm{Pt} / \mathrm{C}_{\mathrm{TKK}}(18.2 \%)$. Hence, the positron annihilation probability with $\mathrm{Pt}$ core electrons is significantly decreased in $\mathrm{Pt} / \mathrm{C}_{\mathrm{TD}}$. This effect is explained by the presence of a higher density of vacancy-like defects in $\mathrm{Pt} / \mathrm{C}_{\mathrm{TD}}$, since positrons are likely to be trapped at vacancies, where, in turn, the annihilation probability with core electrons is reduced. This conclusion is in accordance with the lower density of structural defects in the commercial sample, as observed in the DBS measurements.

Another approach to investigate the presence of structural defects in nanostructured catalysts is the use of high energy X-rays. Indeed, recent studies have used Rietveld refinement of WAXS patterns to extract the microstrain (i.e., the local strain) contribution from the experimental Bragg peak broadening ${ }^{43,44,45}$ Microstrain broadening in diffraction data originates in the local atom displacements from their ideal position, such as caused by atomic vacancies, stacking faults or grain boundaries. ${ }^{46}$ Here, it should be noted that 
at the grain boundary of coalescing particles similarly active concave sites are formed.

Figure S2A displays the WAXS pattern measured at the ID31 beamline of the European synchrotron radiation facility (ESRF, Grenoble, France), including the calculated patterns for the $\mathrm{Pt} / \mathrm{C}_{\mathrm{TD}}$ catalyst (details about the WAXS pattern of the commercial $\mathrm{Pt} / \mathrm{C}_{\mathrm{TKK}}$ catalyst are available in Figure S2B). Results shown in Table S1 unambiguously support the conclusions obtained from DBS measurements: while commercial $\mathrm{Pt} / \mathrm{C}_{\mathrm{TKK}}$ features zero value of microstrain, a value of $0.60 \%$ is found for $\mathrm{Pt} / \mathrm{C}_{\mathrm{TD}}$ (being comparable or higher than some PtNi alloyed samples) ${ }^{45}$ confirming its highly defective structure. The resulting surface distortion (SD) value was derived as $3.9 \pm 0.2 \%$ for the synthesized $\mathrm{Pt} / \mathrm{C}_{\mathrm{TD}}$ (for further information see reference 45). It has to be noted that both techniques are not solely surface sensitive, but partially also include bulk information.

Electrochemical measurements further validate the presence of structural surface defects. Figure $2 \mathrm{C}$ and $\mathrm{D}$ shows typical cyclic voltammograms (CVs) of $\mathrm{Pt} / \mathrm{C}_{\mathrm{TD}}$ and commercial $\mathrm{Pt} / \mathrm{C}_{\mathrm{TKK}}$. In both cases, in the potential range of $\sim 0.05-0.40 \mathrm{~V} v s$ the reversible hydrogen electrode $(\mathrm{RHE})$, typical hydrogen adsorption and desorption $\left(\mathrm{H}_{\mathrm{ads} / \mathrm{des}}\right)$ features 
of polycrystalline $\mathrm{Pt}$ are visible. In detail, commercial $\mathrm{Pt} / \mathrm{C}_{\mathrm{TKK}}$ depicts a sharp peak doublet with maxima at $\sim 0.15$ and $\sim 0.22 \mathrm{~V} v s$ RHE (red dotted lines). According to Vidal-Iglesias et al., using $\mathrm{HClO}_{4}$ as an electrolyte, features in the range between $0.09 \mathrm{~V}$ and $0.22 \mathrm{~V} v s$ RHE can be addressed to the $H_{\text {ads/des }}$ on $\mathrm{Pt}(110)$ facets, while the impact of (111) and (100) facets cannot be clearly attributed. ${ }^{47}$ Contrary, $P t / C_{T D}$ shows an additional distinct peak shoulder at $\sim 0.27 \vee v s$ RHE (orange dotted line), which can be assigned to the $\mathrm{H}_{\mathrm{ads} / \mathrm{des}}$ on defective surface structures, as proposed by Chattot $e t$ al. ${ }^{44}$ Herein, we assume that the broad $\mathrm{H}_{\text {des }}$ peak structure provides further evidence for the presence of structural defects on the $\mathrm{Pt}_{\mathrm{TD}}$ nanoparticle surface.

CO-stripping voltammograms of both commercial $\mathrm{Pt} / \mathrm{C}_{T K K}$ and $\mathrm{Pt} / \mathrm{C}_{\mathrm{TD}}$ are shown in Figure $2 \mathrm{E}$. While the commercial $\mathrm{Pt} / \mathrm{C}$ only shows a single peak at a potential of $\sim 0.78 \mathrm{~V} v s \mathrm{RHE}$, indicating majorly isolated, well-distributed nanoparticles, $\mathrm{Pt} / \mathrm{C}_{\mathrm{TD}}$ shows a peak doublet with maxima located at $\sim 0.67 \mathrm{~V}$ and $\sim 0.69 \mathrm{~V} v s$ RHE and a singlet at a potential slightly lower than $0.78 \mathrm{~V} v s \mathrm{RHE}$. Based on the findings of Maillard et al., appearance of the peak doublet structure at lower potentials can be traced back to the presence of structural 
defects on complex isolated as well as agglomerated nanoparticles..$^{44,48}$ Recently, Chattot et al. compared the ratio between charge $\mathrm{Q}$ derived from $\mathrm{CO}_{\text {ads }}$ and $\mathrm{H}_{\text {ads/des }}$ peaks with the level of SD of different Pt-based ORR nanocatalysts, indicating a quasi-linear relationship. ${ }^{49}$ Taken the proposed evaluation protocols into account, $\mathrm{Pt} / \mathrm{C}_{\mathrm{TD}}$ catalyst shows a $Q_{C O} / 2 Q_{H}$ ratio of $0.85 \pm 0.4$, which indicates high density of surface defects and is comparable to e.g., hollow PtNi/C.
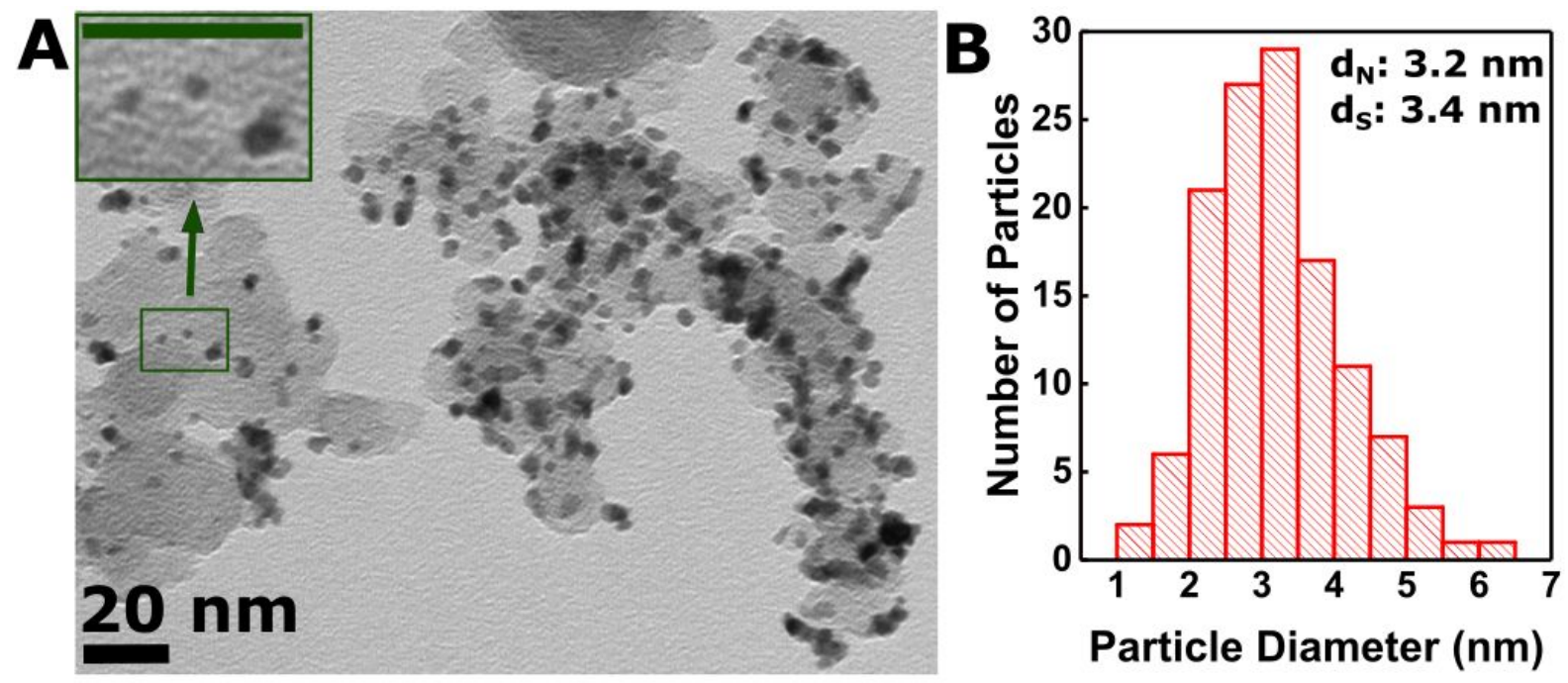

Figure 3. (A) TEM image of $P t / C_{T D}$. The image reveals a homogeneous $P t$ nanoparticle coverage of the carbon support, however, parts of the support are less densely covered than others. The inset shows a magnification of some particles marked by a green frame (green scale bar: $20 \mathrm{~nm}$ ). (B) Corresponding PSD of $\mathrm{Pt} / \mathrm{C}_{\mathrm{TD}}$, revealing a number- 
averaged diameter $\left(d_{N}\right)$ of $\sim 3.2 \pm 1.0 \mathrm{~nm}$ and a surface-averaged diameter $\left(\mathrm{d}_{\mathrm{S}}\right)$ of $\sim 3.4$

$\mathrm{nm}$. The PSD was derived from the investigation of 125 isolated Pt nanoparticles.

Previously mentioned observations can be further validated by observations derived from

TEM imaging, as depicted in Figure 3A. Indeed, several small Pt nanoparticle agglomerates can be observed. Overall, the Pt nanoparticles are homogeneously distributed on Vulcan carbon, however, Pt nanoparticle density partially varies. The image shows that next to particles in the size range of 3-6 nm, several smaller particles with diameter $\leq 2$ $\mathrm{nm}$ can be observed. The corresponding particle size distribution (PSD) from the investigation of 125 isolated nanoparticles is given in Figure 3B, taking into account both edges of each individual particle and no particle agglomerates. PSD analysis was performed using the ImageJ software. Based on the broad size distribution, the numberaveraged $\left(d_{N}\right)$ and surface-averaged $\left(d_{S}\right)$ diameter of the isolated Pt nanoparticles was determined to be $\sim 3.2 \pm 1.0 \mathrm{~nm}$ and $\sim 3.4 \mathrm{~nm}$, respectively. In case of the commercial $\mathrm{Pt} / \mathrm{C}_{\mathrm{TKK}}$ sample used, a number-averaged diameter of $\sim 2.8 \pm 0.8 \mathrm{~nm}$ can be found in the literature.$^{50}$ In contrast to the mean size determined from TEM, WAXS shows a global average 
size of $8.3 \mathrm{~nm}$ (Table S1), which indicates a bimodal size distribution consisting of smaller, isolated nanoparticles and larger particle aggregates. Similar observations have previously been reported by Chattot et al., where partially aggregated A-Pt/C electrocatalyst showed a TEM derived mean particle size of $3.4 \mathrm{~nm}$, while WAXS revealed a global average size of $7.4 \mathrm{~nm} .{ }^{45}$

In order to evaluate the electrocatalytic activity of $\mathrm{Pt} / \mathrm{C}_{\mathrm{TD}}$ towards the ORR, RDE measurements of freshly prepared catalyst inks were conducted. A typical polarization curve of $\mathrm{Pt} / \mathrm{C}_{\mathrm{TD}}$ is depicted in Figure 4A. Evaluation of the kinetic current was performed using the Koutecký -Levich equation (Equation 1)

$$
I_{\text {kin }}=\left|\left(I \cdot I_{\text {lim }}\right)\right| /\left|\left(I_{\text {lim }}-I\right)\right|(1)
$$

with $/$ being the measured current, $I_{k i n}$ being the kinetic current and $I_{\text {lim }}$ being the $\mathrm{O}_{2}$ diffusion-limited current of the polarization curve. The kinetic current curve extracted from the polarization curve in a range of $0.85 \mathrm{~V}-1.0 \mathrm{~V}$ is shown in the inset of Figure $4 \mathrm{~A}$. The corresponding analysis of commercial $\mathrm{Pt} / \mathrm{C}_{\mathrm{TKK}}$ is depicted in Figure S3. As described earlier, due to the high concentration of surface structural defects of $\mathrm{Pt} / \mathrm{C}_{\mathrm{TD}}$, we predict an activity increase compared to commercial $\mathrm{Pt} / \mathrm{C}$. Indeed, at $0.90 \mathrm{~V} v s \mathrm{RHE}$, we observe a 3.6-times enhanced mass activity $\left(\sim 712 \pm 20 \mathrm{~mA} / \mathrm{mg}_{\mathrm{Pt}}\right)$ and a $\sim 6.8$-times enhanced 
specific activity $\left(\sim 1.62 \pm 0.32 \mathrm{~mA} / \mathrm{cm}^{2}{ }_{\mathrm{Pt}}\right)$ of $\mathrm{Pt} / \mathrm{C}_{\mathrm{TD}}$ compared to commercial $\mathrm{Pt} / \mathrm{C}_{\mathrm{E} \text {-tek }}$ (activity values taken from literature), ${ }^{51,52}$ and $\sim 1.7$-times mass, $\sim 2.7$-times specific activity enhancement compared to $\mathrm{Pt} / \mathrm{C}_{\mathrm{TKK}}$. The activities of $\mathrm{Pt} / \mathrm{C}_{\mathrm{TKK}}$ are in good agreement with literature values of the same catalyst, considering the impact of the ionomer concentration. ${ }^{53}$ This is a significant improvement over typically used $\mathrm{Pt} / \mathrm{C}$ electrocatalysts, especially as the activity is compared to one of the most active commercial Pt/C catalysts. Moreover, the activity is even comparable to some well-known PtNi and PtCo alloyed electrocatalysts..$^{54,55}$

\begin{abstract}
Regarding the stability of $\mathrm{Pt} / \mathrm{C}_{\mathrm{TD}}$, preliminary accelerated durability tests of $\mathrm{Pt} / \mathrm{C}_{\mathrm{TKK}}$ and $\mathrm{Pt} / \mathrm{C}_{\mathrm{TD}}$ were conducted in RDE configuration. After 10,000 cycles between 0.6 and $1.0 \mathrm{~V}$ vs RHE, performed at $80^{\circ} \mathrm{C}, \mathrm{Pt} / \mathrm{C}_{\mathrm{TD}}$ still shows higher activity than $\mathrm{Pt} / \mathrm{C}_{\mathrm{TKK}}$ (Figure $\mathrm{S} 4 \mathrm{~A}$ ). As expected, post-mortem $\mathrm{TEM}$ analysis of $\mathrm{Pt} / \mathrm{C}_{\mathrm{TD}}$ shows strong particle sintering at elevated temperature. Moreover, isolated particles appear to become more spherical (Figure S4B).
\end{abstract}


A

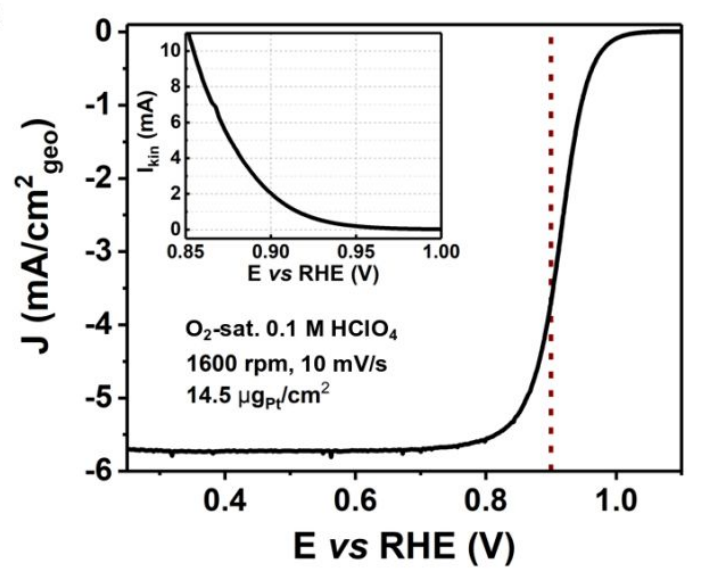

B

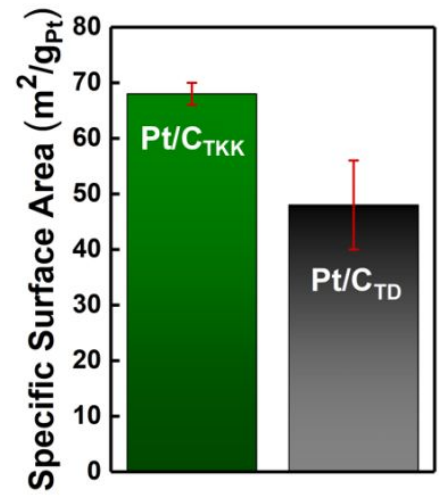

C

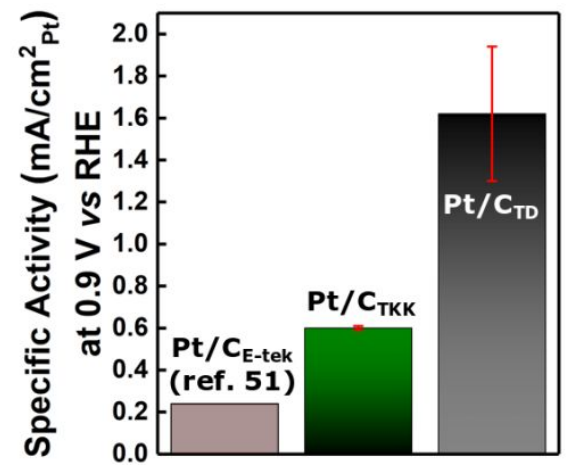

D

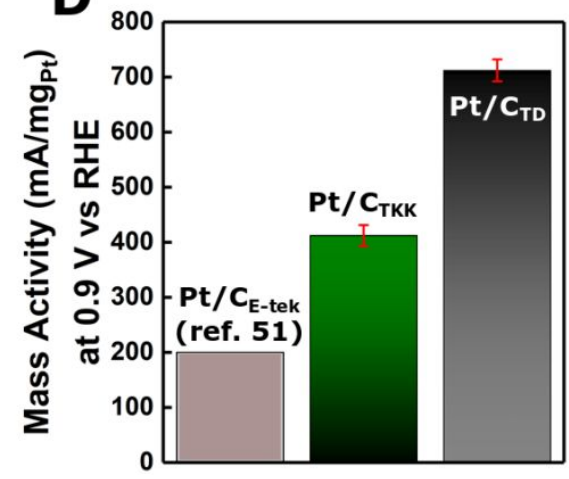

Figure 4. (A) Typical IR-corrected polarization curve of $\mathrm{Pt} / \mathrm{C}_{\mathrm{TD}}$ (anodic scan). Electrolyte: $\mathrm{O}_{2}$-saturated $0.1 \mathrm{M} \mathrm{HClO}_{4}$. Scan rate: $10 \mathrm{mV} / \mathrm{s}$. Rotational speed: 1600 rpm. Pseudo-capacitive currents were corrected by subtraction of a background CV. The measurement is normalized to the geometrical area of the glassy carbon electrode used in the experiments $\left(0.196 \mathrm{~cm}^{2}\right)$ and an electrode loading of $\sim 14.5 \mu \mathrm{g}_{\mathrm{Pt}} / \mathrm{cm}^{2}$ was adjusted. The corresponding kinetic current curve in a potential range of $0.85-1.00 \mathrm{~V}$ vs RHE is displayed in the inset of the graph. (B) SSA of Pt/C $\mathrm{TD}_{\mathrm{TD}}$ compared to the SSA 
of commercial $\mathrm{Pt} / \mathrm{C}_{\mathrm{TKK}}$. (C) Specific activity of $\mathrm{Pt} / \mathrm{C}_{\mathrm{TD}}$ compared to commercial $\mathrm{Pt} / \mathrm{C}_{\mathrm{E}-\text { tek }}$ (activity value taken from ref. 51, benchmarked under similar conditions) and $\mathrm{Pt} / \mathrm{C}_{\mathrm{TKK}}$ at $0.9 \mathrm{~V}$ vs $\mathrm{RHE}$. (D) Mass activity of $\mathrm{Pt} / \mathrm{C}_{\mathrm{TD}}$ compared to commercial $\mathrm{Pt} / \mathrm{C}_{\mathrm{E} \text {-tek }}$ (activity value taken from ref. 51, benchmarked under similar conditions) and $\mathrm{Pt}_{\mathrm{t}} \mathrm{C}_{\mathrm{TKK}}$ at $0.9 \mathrm{~V}$ vs RHE.

To determine the specific activity of $\mathrm{Pt} / \mathrm{C}_{\mathrm{TD}}$, the kinetic current at $0.90 \mathrm{~V} v s \mathrm{RHE}$ was normalized to the electrochemically active surface area (ECSA) of the catalyst. Integration of the $\mathrm{H}_{\text {UPD }}$ charge of each CV was used to determine the ECSA. For the ad- and desorption of a monolayer of $\mathrm{H}$ on $\mathrm{Pt}$, a charge density of $210 \mu \mathrm{C} / \mathrm{cm}^{2} \mathrm{Pt}$ was assumed.

Determination of the mass activity was conducted by normalizing the kinetic current to the Pt mass deposited on the working electrode.

The specific surface area (SSA) of $\mathrm{Pt} / \mathrm{C}_{\mathrm{TD}}$ was determined to be $\sim 46 \pm 8 \mathrm{~m}^{2} / \mathrm{g}_{\mathrm{Pt}}$, while commercial $\mathrm{Pt} / \mathrm{C}_{\mathrm{TKK}}$ exhibits an SSA of $\sim 68 \pm 2 \mathrm{~m}^{2} / \mathrm{g}_{\mathrm{Pt}}$ (being comparable to literature data, considering the impact of the ionomer concentration). ${ }^{53}$ In both cases, the SSA was normalized to the catalyst mass deposited on the working electrode. Comparing the 
average size of both catalysts, only a slightly reduced SSA compared to $\mathrm{Pt} / \mathrm{C}_{\mathrm{TKK}}$ is expected. Hence, we assume that the actual difference in SSA is partially caused by agglomeration of the Pt nanoparticles, as can be seen in Figure $3 \mathrm{~A}$. The activity data and SSA values of $\mathrm{Pt} / \mathrm{C}_{\mathrm{TD}}$ and commercial $\mathrm{Pt} / \mathrm{C}$ are compared in Figure 4B-D.

To further investigate the performance of $\mathrm{Pt} / \mathrm{C}_{\mathrm{TD}}$ in an actual membrane electrode assembly (MEA), preliminary measurements in a single-cell PEMFC were conducted. To meet current industrial targets to produce PEMFCs with low Pt content, MEAs with a cathode loading of $\sim 0.1 \mathrm{mg}_{\mathrm{Pt}} / \mathrm{cm}^{2}$ were prepared and examined. The results are shown in Figure 5. Figure 5A depicts the CO-stripping voltammogram of the $\mathrm{Pt} / \mathrm{C}_{\mathrm{TD}}$ catalyst layer.

As observed in the RDE measurements, the voltammogram shows a characteristic double peak between $0.6 \mathrm{~V}$ and $0.9 \mathrm{~V}$, associated with surface defects. Evaluation of the SSA gives a value of $\sim 26.5 \mathrm{~m}^{2} / \mathrm{g}_{\mathrm{Pt}}$, being $\sim 40 \%$ lower than the values measured in the RDE tests (assumed standard charge of a CO monolayer on Pt: $420 \mu \mathrm{C} / \mathrm{cm}^{2}$ ). This observation can be due to the increased catalyst batch size, leading to stronger agglomeration of the $\mathrm{Pt}$ nanoparticles, or due to non-uniform ionomer wetting of the 
catalyst layer in the MEA. The ORR kinetics of $\mathrm{Pt} / \mathrm{C}_{\mathrm{TD}}$ were extracted from the $\mathrm{H}_{2} / \mathrm{O}_{2}$ polarization curves after correction of the IR-drop and the $\mathrm{H}_{2}$ crossover. At $0.9 \mathrm{~V}$, a noticeable increase of the mass activity compared to $\mathrm{Pt} / \mathrm{C}_{\mathrm{TKK}}$ (Figure $5 \mathrm{~B}, \mathrm{C}$; reference data measured in the same setup under identical conditions were taken from literature ${ }^{56}$ ) can be observed, validating the results obtained from RDE studies. Owed to the so-called particle size effect, the specific activity of both catalysts is poorly comparable, as the SSA of $\mathrm{Pt} / \mathrm{C}_{\mathrm{TKK}}$ is more than 2.5-times larger than the SSA of $\mathrm{Pt} / \mathrm{C}_{\mathrm{TD}} .{ }^{56,57}$ Hence, in order to compare the intrinsic activity of $\mathrm{Pt} / \mathrm{C}_{\mathrm{TD}}$, we included the activity data of heat-treated $\mathrm{Pt} / \mathrm{C}_{\mathrm{TKK}}$ recorded by Schwämmlein et al. (HT-Pt/ $\mathrm{C}_{\mathrm{TKK}}$, taken from literature $\left.{ }^{56}\right)$ with an SSA of $\sim 7 \mathrm{~m}^{2} / \mathrm{g}_{\mathrm{Pt}}$. Due to the smaller SSA of $\mathrm{HT}-\mathrm{Pt} / \mathrm{C}_{\mathrm{TKK}}$, higher specific activity is expected. However, at $0.9 \mathrm{~V}$ we still observe higher specific activity of $\mathrm{Pt} / \mathrm{C}_{\mathrm{TD}}$ compared to HT$\mathrm{Pt} / \mathrm{C}_{\mathrm{TKK}}$, indicating higher intrinsic activity of $\mathrm{Pt} / \mathrm{C}_{\mathrm{TD}}$. While at $0.9 \mathrm{~V}$ only kinetic losses are expected, at higher current densities the low roughness factor $\left(\mathrm{cm}^{2}{ }_{\mathrm{Pt}} / \mathrm{cm}^{2}\right.$ MEA $)$ leads to a poor $\mathrm{O}_{2}$ mass transport, as previously reported by Harzer, Schwämmlein et al.50,56 Here, in particular proper wetting of the catalyst layer with ionomer has to be ensured in order to prevent losses. Thus, we assume that for up-scaled batch sizes, enhancing the SSA 
of $\mathrm{Pt} / \mathrm{C}_{\mathrm{TD}}$ through an improved synthesis procedure (e.g., improved mixing of the electrolyte during synthesis) and adjustment of the ionomer distribution could further improve the performance of the catalyst, especially at high current densities. Moreover, in future experimental studies, the stability of defect-rich $\mathrm{Pt} / \mathrm{C}_{\mathrm{TD}}$ in the MEA setup has to be evaluated, as this task was out of the scope of this work. However, accelerated stress tests of Schwämmlein et al. indicate that in the MEA, a lower SSA has beneficial effects on the stability of the catalyst, which should be considered prior to adjustment of the surface area. ${ }^{56}$ 

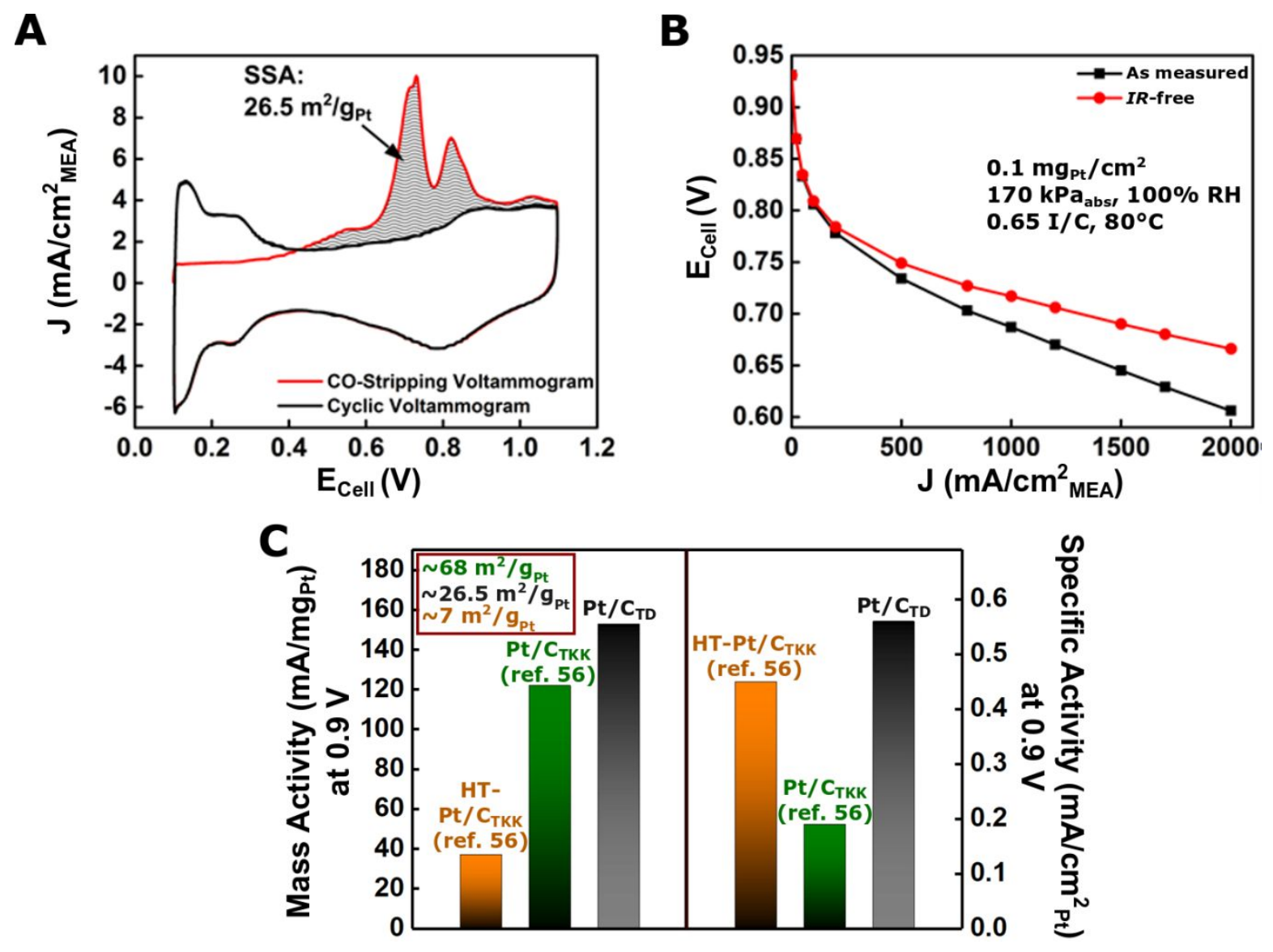

Figure 5. (A) CO-stripping voltammogram of the $\mathrm{Pt} / \mathrm{C}_{\mathrm{TD}}$ cathode catalyst layer, showing a characteristic double peak. Integration of the peaks and normalization to Pt mass leads to a SSA of $\sim 26.5 \mathrm{~m}^{2} / \mathrm{g}_{\mathrm{Pt}}$. (B) Uncorrected and $/ R$-corrected $\mathrm{H}_{2} / \mathrm{O}_{2}$ differential flow polarization curve of the $\mathrm{Pt} / \mathrm{C}_{\mathrm{TD}^{-}}$-based MEA $\left(0.1 \mathrm{mg}_{\mathrm{Pt}} / \mathrm{cm}^{2}, 0.65 \mathrm{l} / \mathrm{C}\right.$ ratio), recorded at a pressure of $170 \mathrm{kPa}_{\mathrm{abs}}, 80^{\circ} \mathrm{C}$ and $100 \%$ relative humidity (RH). (C) Mass and specific activity of $\mathrm{Pt} / \mathrm{C}_{\mathrm{TD}}$ at $0.9 \mathrm{~V}$, compared to $\mathrm{Pt} / \mathrm{C}_{\mathrm{TKK}}\left(\mathrm{SSA}: \sim 68 \mathrm{~m}^{2} / \mathrm{g}_{\mathrm{Pt}}\right.$ ) and heat-treated $\mathrm{Pt} / \mathrm{C}_{\mathrm{TKK}}\left(\mathrm{SSA}: \sim 7 \mathrm{~m}^{2} / \mathrm{g}_{\mathrm{Pt}}\right)$. For activity evaluation, the $\mathrm{H}_{2} / \mathrm{O}_{2}$ data were corrected for the 
IR-drop and the $\mathrm{H}_{2}$ crossover current. The reference data were taken from reference 56, however, the catalyst was examined in the same setup and under identical conditions.

\section{Conclusions}

Within this work, we show an up-scalable, top-down and one-pot synthetic approach towards highly active Pt/C electrocatalysts, circumventing typical demanding multi-step synthesis procedures. In $\mathrm{RDE}$ studies, synthesized $\mathrm{Pt} / \mathrm{C}_{\mathrm{TD}}$ shows high activity towards the $\mathrm{ORR}$ with a specific and mass activity of $1.62 \mathrm{~mA} / \mathrm{cm}^{2}{ }_{\mathrm{Pt}}$ and $712 \mathrm{~mA} / \mathrm{mg}_{\mathrm{Pt}}$, respectively. An ORR activity enhancement over commercial Pt/C was further confirmed in a single-cell PEMFC. Based on TEM, WAXS, CV and PAS experiments, the origin of the superior activity compared to commercial Pt/C can be correlated to the introduction of a high density of surface defects, such as surface concavities. Furthermore, considering the high complexity of classical nucleation driven bottom-up syntheses and costs of the precursor materials, the top-down approach does not only facilitate the synthesis, but should also save overall processing costs in large scale applications.

\section{ASSOCIATED CONTENT}

\section{Supporting Information}




\author{
This information is available free of charge on the ACS Publications website. Coincident Doppler \\ broadening spectrum, WAXS measurements, Rietveld refinement data, Reference ORR \\ polarization curve, Accelerated durability test, TEM analysis
}

AUTHOR INFORMATION

Corresponding Author

*E-mail: bandarenka@ph.tum.de. Phone: +49 (0) 8928912531.

\begin{abstract}
Author Contributions
The manuscript was written through contributions of all authors. All authors have given approval to the final version of the manuscript. $\ddagger$ These authors contributed equally to this work.
\end{abstract}

Notes

The authors declare no competing financial interest.

ACKNOWLEDGEMENT 
We gratefully acknowledge the financial support from Deutsche Forschungsgemeinschaft

(DFG, German Research Foundation) under Germany's excellence strategy - EXC

2089/1 - 390776260, Germany's excellence cluster "e-conversion", DFG projects BA

5795/4-1 and BA 5795/3-1, and from the TUM International Graduate School of Science

and Engineering, project 11.01. Support from CEITEC Nano Research Infrastructure and

Karlsruhe Nano Micro Facility as well as financial support from Ministry of Youth, Education

and Sports of the Czech Republic, projects LM2015041 and LQ1601, are gratefully acknowledged.

W.-J. Li gratefully acknowledges the financial support from the Alexander von Humboldt

fellowship for postdoctoral researchers. We thank Prof. Hubert A. Gasteiger for providing

reference electrocatalyst samples and for providing access to his fuel cell test equipment.

We are thankful to Jan N. Schwämmlein for conducting the fuel cell test measurements.

We thank Prof. Hendrik Dietz for granting access to his transmission electron microscopy facilities.

TOC: 
Tailoring the Oxygen Reduction Activity of Pt Nanoparticles through Surface Defects: A Simple Top-Down Approach

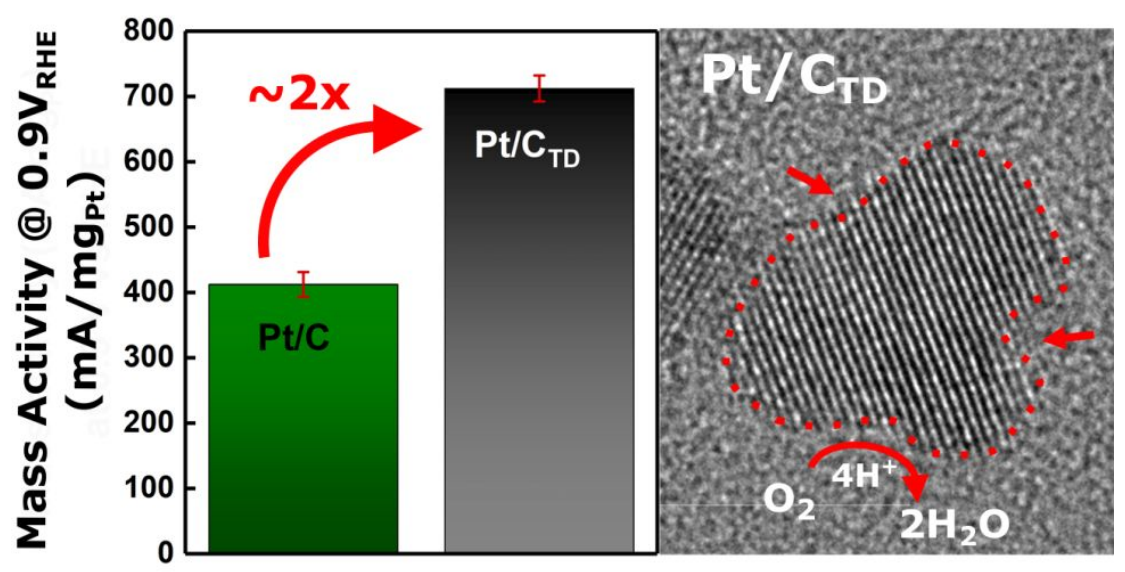

REFERENCES

(1) Thomas, C. E. Fuel Cell and Battery Electric Vehicles Compared. Int. J. Hydrog. Energy 2009, 34, 6005-6020.

(2) Pellow, M. A.; Emmott, C. J. M.; Barnhart, C. J.; Benson, S. M. Hydrogen or Batteries for Grid Storage? A Net Energy Analysis. Energy Environ. Sci. 2015, 8, 1938-1952.

(3) Yoshida, T.; Kojima, K. Toyota MIRAI Fuel Cell Vehicle and Progress Toward a Future Hydrogen Society. Electrochem. Soc. Interface 2015, 24, 45-49. 
(4) Chen, S.; Sheng, W.; Yabuuchi, N.; Ferreira, P. J.; Allard, L. A.; Shao-Horn, Y. Origin of Oxygen Reduction Reaction Activity on " $\mathrm{Pt}_{3} \mathrm{Co"}$ Nanoparticles: Atomically Resolved Chemical Compositions and Structures. J. Phys. Chem. C 2009, 113, 1109-1125.

(5) Oezaslan, M.; Hasché, F.; Strasser, $\mathrm{P} . \mathrm{PtCu}_{3}, \mathrm{PtCu}$ and $\mathrm{Pt}_{3} \mathrm{Cu}$ Alloy Nanoparticle Electrocatalysts for Oxygen Reduction Reaction in Alkaline and Acidic Media. $J$. Electrochem. Soc. 2012, 159, B444-B454.

(6) Garlyyev, B.; Pohl, M. D.; Čolić, V.; Liang, Y.; Butt, F. K.; Holleitner, A.; Bandarenka, A. S. High Oxygen Reduction Reaction Activity of $\mathrm{Pt}_{5} \mathrm{Pr}$ Electrodes in Acidic Media. Electrochem. Commun. 2018, 88, 10-14.

(7) Stephens, I. E. L.; Bondarenko, A. S.; Grønbjerg, U.; Rossmeis1, J.; Chorkendorff, I. Understanding the Electrocatalysis of Oxygen Reduction on Platinum and its Alloys. Energy Environ. Sci. 2012, 5, 6744-6762.

(8) Kitchin, J. R.; Nørskov, J. K.; Barteau, M. A.; Chen, J. G. Role of Strain and Ligand Effects in the Modification of the Electronic and Chemical Properties of Bimetallic Surfaces. Phys. Rev. Lett. 2004, 93, 156801.

(9) Bligaard, T.; Nørskov, J. K. Ligand Effects in Heterogeneous Catalysis and Electrochemistry. Electrochim. Acta 2007, 52, 5512-5516.

(10) Stamenkovic, V.R.; Fowler, B.; Mun, B. S.; Wang, G.; Ross, P. N.; Lucas, C. A.; Marković, N. M. Improved Oxygen Reduction Activity on $\mathrm{Pt}_{3} \mathrm{Ni}(111)$ via Increased Surface Site Availability. Science 2007, 315, 493-497.

(11) Zhang, J.; Yang, H.; Fang, J.; Zou, S. Synthesis and Oxygen Reduction Activity of ShapeControlled $\mathrm{Pt}_{3} \mathrm{Ni}$ Nanopolyhedra. Nano Lett. 2010, 10, 638-644. 
(12) Mi, S.; Cheng, N.; Jiang, H.; Li, C.; Jiang, H. Porous $\mathrm{Pt}_{3} \mathrm{Ni}$ with Enhanced Activity and Durability Towards Oxygen Reduction Reaction. RSC Adv. 2018, 8, 15344-15351.

(13) Durst, J.; Chatenet, M.; Maillard, F. Impact of Metal Cations on the Electrocatalytic Properties of Pt/C Nanoparticles at Multiple Phase Interfaces. Phys. Chem. Chem. Phys. 2012, 14, 13000-13009.

(14) Garlyyev, B.; Kratzl, K.; Rück, M.; Michalička, J.; Fichtner, J.; Macak, J. M.; Kratky, T.; Günther, S.; Cokoja, M.; Bandarenka, A. S.; Gagliardi, A.; Fischer, R. A. Optimizing the Size of Platinum Nanoparticles for Enhanced Mass Activity in the Electrochemical Oxygen Reduction Reaction. Angew. Chem. Int. Ed. 2019, 58, 9596-9600.

(15) Dubau, L.; Asset, T.; Chattot, R.; Bonnaud, C.; Vanpeene, V.; Nelayah, J.; Maillard, F. Tuning the Performance and the Stability of Porous Hollow PtNi/C Nanostructures for the Oxygen Reduction Reaction. ACS Catal. 2015, 5, 5333-5341.

(16) Henning, S.; Kühn, L.; Herranz, J.; Durst, J.; Binninger, T.; Nachtegaal, M.; Werheid, M.; Liu, W.; Adam, M.; Kaskel, S.; Eychmüller, A.; Schmidt, T. J. Pt-Ni Aerogels as Unsupported Electrocatalysts for the Oxygen Reduction Reaction. J. Electrochem. Soc. 2016, 163, F998-F1003.

(17) Calle-Vallejo, F.; Pohl, M. D.; Reinisch, D.; Loffreda, D.; Sautet, P.; Bandarenka, A. S. Why Conclusions from Platinum Model Surfaces Do Not Necessarily Lead to Enhanced Nanoparticle Catalysts for the Oxygen Reduction Reaction. Chem. Sci. 2017, 8, 2283-2289. 
(18) Calle-Vallejo, F.; Tymoczko, J.; Colic, V.; Vu, Q. H.; Pohl, M. D.; Morgenstern, K.; Loffreda, D.; Sautet, P.; Schuhmann, W.; Bandarenka, A. S. Finding Optimal Surface Sites on Heterogeneous Catalysts by Counting Nearest Neighbors. Science 2015, 350, 185-189.

(19) Yu, T.; Kim, D. Y.; Zhang, H.; Xia, Y. Platinum Concave Nanocubes with High-Index Facets and Their Enhanced Activity for Oxygen Reduction Reaction. Angew. Chem. Int. Ed. 2011, 50, $2773-2777$.

(20) Chen, A.; Holt-Hindle, P. Platinum-Based Nanostructured Materials: Synthesis, Properties, and Applications. Chem. Rev. 2010, 110, 3767-3804.

(21) Bredig, G.; Haber, F. Ueber Zerstäubung von Metallkathoden bei der Elektrolyse mit Gleichstrom. Eur. J. Inorg. Chem. 1898, 31, 2741-2752.

(22) Yanson, A. I.; Rodriguez, P.; Garcia-Araez, N.; Mom, R. V.; Tichelaar, F. D.; Koper, M. T. M. Cathodic Corrosion: A Quick, Clean, and Versatile Method for the Synthesis of Metallic Nanoparticles. Angew. Chem. Int. Ed. 2011, 50, 6346-6350.

(23) Feng, J.; Chen, D.; Sediq, A. S.; Romeijn, S.; Tichelaar, F. D.; Jiskoot, W.; Yang, J.; Koper, M. T. M. Cathodic Corrosion of a Bulk Wire to Nonaggregated Functional Nanocrystals and Nanoalloys. ACS Appl. Mater. Interfaces 2018, 10, 9532-9540.

(24) Huang, W.; Chen, S.; Zheng, J.; Li, Z. Facile Preparation of Pt Hydrosols by Dispersing Bulk Pt with Potential Perturbations. Electrochem. Commun. 2009, 11, 469-472.

(25) Chen, X.; Chen, S.; Huang, W.; Zheng, J.; Li, Z. Facile Preparation of Bi Nanoparticles by Novel Cathodic Dispersion of Bulk Bismuth Electrodes. Electrochim. Acta 2009, 54, 73707373.

(26) Fichtner, J.; Garlyyev, B.; Watzele, S.; El-Sayed, H. A.; Schwämmlein, J. N.; Li, W.; Maillard, F.; Dubau, L.; Michalička, J.; Macak, J.; Holleitner, A.; Bandarenka, A. S. 
Top-Down Synthesis of Nanostructured Platinum-Lanthanide Alloy Oxygen Reduction Reaction Catalysts: $\mathrm{Pt}_{\mathrm{x}} \mathrm{Pr} / \mathrm{C}$ as an Example. ACS Appl. Mater. Interfaces 2019, 11, 5129-5135.
(27) Hugenschmidt, C.; Löwe, B.; Mayer, J.; Piochacz, C.; Pikart, P.; Repper, R.; Stadlbauer, M.; Schreckenbach, K. Unprecedented Intensity of a Low-Energy Positron Beam. Nucl. Instrum. Meth. 2008, 593, 616-618.
(28) Gigl, T.; Beddrich, L.; Dickmann, M.; Rienäcker, B.; Thalmayr, M.; Vohburger, S.; Hugenschmidt, C. Defect Imaging and Detection of Precipitates Using a New Scanning Positron Microbeam. New J. Phys. 2017, 19, 123007.
(29) Hugenschmidt, C.; Ceeh, H.; Gigl, T.; Lippert, F.; Piochacz, C.; Pikart, P.; Reiner, M.; Weber, J.; Zimnik, S. The Upgrade of the Neutron Induced Positron Source NEPOMUC. J. Phys.: Conf. Ser. 2013, 443, 12079.
(30) Ashiotis, G.; Deschildre, A.; Nawaz, Z.; Wright, J. P.; Karkoulis, D.; Picca, F. E.; Kieffer, J. The Fast Azimuthal Integration Python Library: PyFAI. J. Appl. Crystallogr. 2015, 48, $510-519$.
(31) Rodríquez-Carvajal, J.; Roisnel, T. Line Broadening Analysis Using FullProf*: Determination of Microstructural Properties. Mater. Sci. Forum 2009, 443, 123-126.

(32) Davey, W. P. Precision Measurements of the Lattice Constants of Twelve Common Metals. Phys. Rev. 1925, 25, 753-761.
(33) Nellist, P. D.; Pennycook, S. J. The Principles and Interpretation of Annular Dark-Field Z- Contrast Imaging. Adv. Imag. Elect. Phys. 2000, 113, 147-203.


(34) Sneed, B. T.; Cullen, D. A.; Reeves, K. S.; Dyck, O.E.; Langlois, D. A.; Mukundan, R.; Borup, R. L.; More, K. L. 3D Analysis of Fuel Cell Electrocatalyst Degradation on Alternate Carbon Supports. ACS Appl. Mater. Interfaces 2017, 9, 29839-29848.

(35) Mayrhofer, K. J.; Meier, J. C.; Ashton, S. J.; Wiberg, G. K.; Kraus, F.; Hanzlik, M.;

Arenz, M. Fuel Cell Catalyst Degradation on the Nanoscale. Electrochem.

Commun. 2018, 10, 1144-1147.

(36) Meier, J. C.; Galeano, C.; Katsounaros, I.; Topalov, A. A.; Kostka, A.; Schüth, F.; Mayrhofer, K. J. Degradation Mechanisms of Pt/C Fuel Cell Catalysts Under Simulated Start-Stop Conditions. ACS Catal. 2012, 2, 832-843.

(37) Coleman, P. Positron Beams and Their Applications, 1st ed.; World Scientific: Singapore, 2000.

(38) Schultz, P. G.; Lynn, K. G. Interaction of Positron Beams with Surfaces, Thin Films, and Interfaces. Rev. Mod. Phys. 1988, 60, 701-779.

(39) Hugenschmidt, C. Positrons in Surface Physics. Surf. Sci. Rep. 2016, 71, 547-594.

(40) Krause-Rehberg, R.; Leipner, H. S. Positron Annihilation in Semiconductors: Defect Studies, 2nd ed.; Springer: Berlin, 2003.

(41) Makhov, A. F. The Penetration of Electrons into Solids. 2. The Distribution of Electrons in Depth. Sov. Phys. Solid State 1961, 2, 1942-1944.

(42) Sanders, I. J.; Peeten, T. L. Carbon Black: Production, Properties, and Uses, 1st ed.; Nova Science Publishers: Hauppauge, 2011. 
(43) Dubau, L.; Nelayah, J.; Moldovan, S.; Ersen, O.; Bordet, P.; Drnec, J.; Asset, T.; Chattot, R.; Maillard, F. Defects Do Catalysis: CO Monolayer Oxidation and Oxygen Reduction Reaction on Hollow PtNi/C Nanoparticles. ACS Catal. 2016, 6, 4673-4684.

(44) Chattot, R.; Asset, T.; Bordet, P.; Drnec, J.; Dubau, L.; Maillard, F. Beyond Strain and Ligand Effects: Microstrain-Induced Enhancement of the Oxygen Reduction Reaction Kinetics on Various PtNi/C Nanostructures. ACS Catal. 2017, 7, 398-408.

(45) Chattot, R.; Le Bacq, O.; Beermann, V.; Kühl, S.; Herranz, J.; Henning, S.; Kühn, L.; Asset, T.; Guétaz, L.; Renou, G.; Drnec, J.; Bordet, P.; Pasturel, A.; Eychmüller, A.; Schmidt, T. J.; Strasser, P.; Dubau, L.; Maillard, F. Surface Distortion as a Unifying Concept and Descriptor in Oxygen Reduction Reaction Electrocatalysis. Nat. Mater. 2018, $17,827-833$.

(46) Qin, W.; Szpunar, J. A. Origin of Lattice Strain in Nanocrystalline Materials. Philos. Mag. Lett. 2005, 85, 649-656.

(47) Vidal-Iglesias, F. J.; Arán-Ais, R. M.; Solla-Gullón, J.; Herrero, E.; Feliu, J. M. Electrochemical Characterization of Shape-Controlled Pt Nanoparticles in Different Supporting Electrolytes. ACS Catal. 2012, 2, 901-910.

(48) Maillard, F.; Schreier, S.; Hanzlik, M.; Savinova, E. R.; Weinkauf, S.; Stimming, U. Influence of Particle Agglomeration on the Catalytic Activity of Carbon-Supported Pt Nanoparticles in CO Monolayer Oxidation. Phys. Chem. Chem. Phys. 2005, 7, 385-393. 
(49) Chattot, R.; Martens, I.; Scohy, M.; Herranz, J.; Drnec, J.; Maillard, F.; Dubau, L.

Disclosing Pt-Bimetallic Alloy Nanoparticle Surface Lattice Distortion with Electrochemical Probes. ACS Energy Lett. 2019, 5, 162-169.

(50) Harzer, G. S.; Schwämmlein, J. N.; Damjanovic, A. M.; Ghosh, S.; Gasteiger, H. A. Cathode Loading Impact on Voltage Cycling Induced PEMFC Degradation: A Voltage Loss Analysis. J. Electrochem. Soc. 2018, 165, F3118-F3131.

(51) Kuttiyiel, K. A.; Sasaki, K.; Choi, Y.; Su, D.; Liu, P.; Adzic, R. R. Bimetallic IrNi Core Platinum Monolayer Shell Electrocatalysts for the Oxygen Reduction Reaction. Energy Environ. Sci. 2012, 5, 5297-5304.

(52) Godínez-Salomón, F.; Rhodes, C. P.; Alcantara, K. S.; Zhu, Q.; Canton, S. E.; Calderon, H. A.; Reyes-Rodríguez, J. L.; Leyva, M. A.; Solorza-Feria, O. Tuning the Oxygen Reduction Activity and Stability of $\mathrm{Ni}(\mathrm{OH})_{2} @ \mathrm{Pt} / \mathrm{C}$ Catalysts through Controlling Pt Surface Composition, Strain, and Electronic Structure. Electrochim. Acta 2017, 247, 958969.

(53) Orfanidi, A.; Madkikar, P.; El-Sayed, H. A.; Harzer, G. S.; Kratky, T.; Gasteiger, H. A. The Key to High Performance Low Pt Loaded Electrodes. J. Electrochem. Soc. 2017, 164, F418-F426.

(54) Mezzavilla, S.; Baldizzone, C.; Swertz, A.-C.; Hodnik, N.; Pizzutilo, E.; Polymeros, G.; Keeley, G. P.; Knossalla, J.; Heggen, M.; Mayrhofer, K. J. J.; Schüth, F. StructureActivity-Stability Relationships for Space-Confined $\mathrm{Pt}_{\mathrm{x}} \mathrm{Ni}_{\mathrm{y}}$ Nanoparticles in the Oxygen Reduction Reaction. ACS Catal. 2016, 6, 8058-8068. 
(55) Pizzutilo, E.; Knossalla, J.; Geiger, S.; Grote, J.-P.; Polymeros, G.; Baldizzone, C.; Mezzavilla, S.; Ledendecker, M.; Mingers, A.; Cherevko, S.; Schüth, F.; Mayrhofer, K. J. J. The Space Confinement Approach Using Hollow Graphitic Spheres to Unveil Activity and Stability of Pt-Co Nanocatalysts for PEMFC. Adv. Energy Mater. 2017, 7, 1700835.

(56) Schwämmlein, J. N.; Harzer, G. S.; Pfändner, P.; Blankenship, A.; El-Sayed, H. A.; Gasteiger, H. A. Activity and Stability of Carbon Supported $\mathrm{Pt}_{\mathrm{x}} \mathrm{Y}$ Alloys for the ORR Determined by RDE and Single-Cell PEMFC Measurements. J. Electrochem. Soc. 2018, $165, \mathrm{~J} 3173-\mathrm{J} 3185$.

(57) Nesselberger, M; Ashton, S.; Meier, J. C.; Katsounaros, I.; Mayrhofer, K. J. J.; Arenz, M. The Particle Size Effect on the Oxygen Reduction Reaction Activity of Pt Catalysts: Influence of Electrolyte and Relation to Single Crystal Models. J. Am. Chem. Soc. 2011, $133,17428-17433$. 